\title{
PHENOMENOLOGICAL CONCEPT OF LAW FROM THE PERSPECTIVE OF CARLOS COSSIO
}

\begin{abstract}
The originality of Cossio's works is expressed by a strong relationship between philosophy of law and his philosophical assumptions. The starting point for deliberating on law are widely recognized ontological and epistemological contentions. Cossio justifies his legal theses basing them on his philosophical views. Egology derives from Edmund Husserl's phenomenology which is related to some elements of William Dilthey's philosophy of culture. Martin Heiddeger's and Immanuel Kant's philosophies are the basis too.

The first part describes Cossio's ontologies of subjects otherwise known as regional ontologies. Methods for examining the above subjects and gnoseological acts are presented here too.

The second part presents the characteristics of law as a cultural subject.

The article is not only a report. Its aim is also to show that Carlos Cossio's legal philosophy is semantic in character.
\end{abstract}

Keywords: phenomenology, egology, legal philosophy, hermeneutics, axiology.

\section{INTRODUCTION}

Carlos Cossio based the egological theory of law on the grounds of the sets of philosophical theses accepted by him. Egology is an example of a philosophical attitude (Wróblewski 1966b) toward the study of law. The originality of its work is represented by the fact that he sees a strong relationship between the philosophy of law and the assumed philosophical premises. As widely recognised ontological and epistemological claims are the starting point for deliberating on law. Moreover, on the ground of assumed philosophical beliefs, Cossio justifies his claims concerning law.

Egology is based on the Edmund Husserl's phenomenology combined with the elements of Wilhelm Dilthey's philosophy of culture and the early period of Martin Heidegger's philosophy, while, in terms of certain concepts, he expressly refers to Immanuel Kant's philosophy. The discussed philosophy of law attempts to understand the place of legal duty in the holistic picture of the reality created mainly on the basis of the phenomenological method.

In the first part, the ontologies of objects (regional ontologies), distinguished by the author of egology, have been described, along with research methods

*The University of Lodz, krzysztof@gozdzialski.com 
and gnoseological acts corresponding with these objects, which those methods comprise. In the second part, I have presented the characteristic of law as a cultural object.

The aim of the presented text is not only to report, but also to demonstrate that Cossio's philosophy of law is of semantic nature.

\section{REGIONAL ONTOLOGIES}

The egological theory derives from the phenomenological description of the "essence" of law. This is due to the fact that the phenomenological method comes down to the study of quintessences. The starting point for Cossio was a specific cognition of essence through the "intuition of essence" which is the intellectual intuition (Cossio 1948, 353). This act is not intuition as such, but a sheer look through reason. Looking through reason we perceive the essence, not the existence of objects (Wróblewski 1957, 1186-1187). The subject of this intuition are "essences", where the egological philosophy of law based on the concept of Husserl's "regional ontologies" classifies objects in several domains which constitute separate regions of being.

Husserl criticised positivists for the fact that while maintaining the attitude inherent in natural sciences, they did not acknowledge the existence of objects different from real objects of external or internal world. In other words, he claimed that a naturalist assumes without research that no matter what type the object of his cognition is, such direct cognition is constantly of the same type - a sensory experience. Phenomenologists questioned such unjustified conviction, indicating that a researcher faced a priori with an opportunity that "...there are numerous basically different objects and that such objects may be directly cognised solely as a result of relevantly different acts of cognition" (Ingarden 1963, 293). Such possibility arises from the existence of sciences different from natural sciences which do not study individual real objects. In the course of research, those kinds of sciences do not apply sensory experience to their practice, however they constitute the pinnacle of accuracy and cognitive confidence. This applies to mathematical sciences and logic.

Therefore, Husserl developed a concept of regional ontologies. He claimed that there was no need for only one category of objects to exist and respectively - only one type of cognition. According to his concept, a defined group of closely related facts creates one domain, one region of a being. Such domain is "subjugated" to one essence constituting the subject of the relevant eidetic science, known as regional ontology. Each facts-related science has its foundations in a relevant regional ontology. Husserl distinguishes material ontologies and formal ontology. Material ontology concerns the essence of objects within one region, in contrast to formal ontology which regards the object as such and includes "common 
formal legislation" for all material ontologies. Each material ontology comprises several most general axioms obtained through the "insight into the being" and applicable to all eidoi and facts of a given region of being. Each domain of a being has a set of such axioms called by Husserl the "entirety of synthetic cognitions a priori" (Martel 1967, 69-70). Thus, the objective of the eidetic phenomenology is to describe various regions of a being, to capture their specific structure, for the specifics of individual sciences and the meaning of their basic notions will be defined. Eidetic laws determine the conditions of the possibility of empirical knowledge, whereby they vary in different regions of a being. They give the sense to the existence of empirical facts constituting the subject of various sciences (Martel 1967, 71).

The characteristic feature of Cossio's philosophy of law is the recognition of law as a cultural object. He claims that culture is a paramount notion against the notion of law; law is in a way "immersed" in culture (Zirk-Sadowski 1977), being its subset. Egology focuses on the general theory of values. Cossio attempts to escape the phenomenological description of the given "essence" of law directly. He studies law mainly in view of axiology (Wróblewski 1969), as he believes that the essence of both law and culture is the realisation of value. The author of the egological theory is therefore an essentialist, for he seeks the characteristic features of law. It originates from the fact that Cossio applies the phenomenological methodology which boils down to the study of the essence of various objects.

Egology determines law based on a specified philosophical foundation, namely the concepts of Husserl's regional ontologies, which, after an essential expansion by Cossio, led to the consideration of law as a cultural object.

Cossio distinguishes four types of objects: ideal, natural, cultural, and metaphysical. He characterises them by means of a triad of features - depending whether they are real or unreal; whether they are given in experience or not; whether they are valuable or neutral to value. I will present below the regional ontologies developed by Cossio, whereby the regional ontology of cultural objects will be presented most broadly, for it is amongst them that egology locates law (Cossio 1948).

Ideal objects are unreal, they do not exist, have no being, and moreover, they are not given in experience, they are beyond time and, ultimately, they are neutral to value, which means that their composition assumes no axiological qualification. There are objects between them that logic and mathematics refer to. For example, an object - a "triangle", which geometry deals with, consists simply in a pure space encapsulated within three lines. The triangle does not exist anywhere, it is not empirically grounded, as triangle of the geometry is not the one which can be drawn in books or on a blackboard. And finally, it is neutral against the value, as the properties of this object, which may only be the geometrical ones, lack any quality such as beauty, health, justice, etc. 
Natural objects, studied by various natural sciences, are real, exist, have a being, are given in experience, are located in time, and neutral to value. Their existence as such is neither good nor bad, neither just nor unjust, neither pretty nor ugly, neither useful nor useless. If one shall consider a stone or a bird, one can freely verify all these features.

Cultural objects or goods created in a way by a human are in turn real, they have a being, exist, are given in experience and located in time. However, they are enriched with a positive or negative sing: right or wrong, pretty or ugly, useful or useless. These are the properties which may define their existence, and such being must always have at least one determination of this class. A charter, instrument or decision, they all fully hold such properties.

Eventually, metaphysical objects are real, they have existence, they exist; they are not given in experience, but may be judged. For example God, recognised as truly material reality and the supreme good, is not given in experience, as He can be neither seen anywhere nor reached with our senses.

The below table presents a synthetic perspective on regional ontologies:

\section{Regional Ontologies}

\begin{tabular}{|c|c|c|c|}
\hline Types of objects & $\begin{array}{c}\text { Characteristics } \\
\text { No 1 }\end{array}$ & $\begin{array}{c}\text { Characteristics } \\
\text { No 2 }\end{array}$ & $\begin{array}{c}\text { Characteristics } \\
\text { No 3 }\end{array}$ \\
\hline ideal & $\begin{array}{c}\text { unreal (irreal), do not } \\
\text { exist }\end{array}$ & $\begin{array}{c}\text { not given in } \\
\text { experience }\end{array}$ & neutral to value \\
\hline natural & $\begin{array}{c}\text { real, have existence } \\
\text { - exist }\end{array}$ & given in experience & neutral to value \\
\hline cultural & $\begin{array}{c}\text { real, have existence } \\
\text { - exist }\end{array}$ & given in experience & $\begin{array}{c}\text { have positive or } \\
\text { negative value }\end{array}$ \\
\hline metaphysical & $\begin{array}{c}\text { real, have existence } \\
\text { - exist }\end{array}$ & $\begin{array}{c}\text { not given in } \\
\text { experience }\end{array}$ & $\begin{array}{c}\text { have positive or } \\
\text { negative value }\end{array}$ \\
\hline
\end{tabular}

Metaphysical objects will be left aside, for their characteristic will not be of any help for the purposes of this article.

Owing to Husserl, we know that an object must be studied with the use of a method which is compatible with its nature (essence). Therefore, the next steps of Cossio on the path of building the regional ontologies are:

1) explanation of various research methodologies related to each of the regions which correspond to ideal, natural, and cultural objects, and

2) exploration and explanation of relevant gnoseological acts, which those methods comprise.

Both of the steps are fundamental. The first step is to show the method of examining, as without the correlation between an object and the method, a research 
work lacks efficient perspective and as ontological differences between them are so enormous and so obvious that they have no common method. The second step is to show the gnoseological act which the method comprises, as such act is the meaning which is translated into each of the methods so that if we do not know it, we will not know what we can get if we apply such method.

\subsection{Ideal Objects}

The truths about ideal objects which logic and mathematics deal with, are, according to Cossio, obtained by application of rational-deductive method (Cossio 1948, 352).

To deduct means to start from one or more of general truths and to draw from them some detailed truth as a conclusion. Transitioning from the general to the detailed is rationally legitimate, as is it based on a reason as a compliance with reason. Therefore, a conclusion cannot be contrary to the premises. Thus, if the deductive method is applied to rational truths, it is entirely relevant for getting the truths. Leibniz's distinction between rational and factual truths is significant. The rational truths are apodictic. It means that they are not only as they are, but must be such, as it is impossible for them to be different. For example, we know that $1+1=2$. It is always like this and cannot be otherwise. On the other hand, factual truth is declaratory; this a truth only because of the fact that things are as they are, happen in this way, but there is no contradiction in the reasoning that it could have been otherwise. For example, when I claim that "the heated metal expands", I tell the truth, as this is what in fact happens, but there is nothing impossible in the assumption that metals could shrink while heated. It is the experience which speaks in the factual truth. If I do not refer to it, I am not able to know what the truth is composed of. On the other hand, a thought speaks in the rational truth. To know that $1+1=2$, I do not have to take two material spheres and calculate them. I only have to think about the issue making no reference to experience.

Cossio concludes that the deductive method is a complete instrument of truth when it is applied to rational truths. But if deduction requires a general principle as a starting point, it means that the method requires a rational truth as its starting point. We have axioms in mathematics, and in logic, the so called paramount logical principles such as equality and non-contradiction. In turn, axiomatic truths do not require proving, as we explore them directly (they are self-evident).

Further, Cossio proceeds to explain what an act of knowledge or gnoseological act is, which constitutes the rational-deductive method, out of which it gets its meaning. He calls this act an "intellection" or an "intellectual intuition" (Cossio 1948, 353). 
Intuition, in general, is a direct contact of the cognising subject with the object being cognised. This is a non-conceptual comprehension of an object in a way which happens not because it is thought about or as the thought mentions it or directs toward the object, but because the object is "in front of us" and because we have it in our direct presence. By means of intuition, we learn about colours, thus one cannot explain to the person blind from birth what in fact the blue colour is. Intuition enables us to cognise things which we see or touch. In general, all organs of our senses are the sources of intuition, but this is a sensory intuition; it should be noted that it is different from the cognition itself as it proves the existence of something which generates experience. We do not experience the existence of a thing, but the existence, in general and with no exceptions, recognises the sensations through sensory intuition and only through it. Existence is also "in front of us" in a direct form and merely because of this fits into the sensory intuition.

Intellectual intuition (intellection) is another type of intuition which we use when the object of cognition is an ideal object. Let us consider the following example:

$$
1+1=2 \quad 12396+15983+17740=46119
$$

These two totals are equally rational truths, and in this sense, they are equally apodictic and both may be presented - or proven - in the same manner. But one can deduce that the first one presents itself to us with its internal directness and fullness of thought as far as we think conceptually, while we capture the second one as if it was seeing the total with our intelligence. The total and its components are in front of our intelligence in their all clarity, in direct and internal form. This is a feature characteristic for mathematical axioms so as such they do not have to be proven. This is what the rational-deductive method is all about; a method which always assumes intellection at the starting point to give us complete truths. This is also a method relevant for all logical principles so the logical intellection is always in compliance with any type of truth as whatever the act of knowledge may be that our reason makes, a logical principle is always used.

The above comments allow Cossio to identify intellection as seeing through reason, by not doing anything else but looking at. The starting point here is a specific act of cognising the "essence" during an act of intellection (Cossio 1948, 353). It is not about intuition here in as commonly understood sense. It consists in "looking through reason", not doing anything more than looking at. One sees an object not through one's eyes, but through one's reason. The object of knowledge is then directly present in front of the intellect. While seeing through one's reason, one does not recognise the existence of the objects, but their essence. 
As Cossio states, "being" which allows for blindness of reason to ideas, is equal to the blindness of senses to things.

The whole intuition, sensory or intellectual one, is characterised by having something personal in it, and thus its course and outcomes may neither be transferred to nor communicated to other cognising objects. In this respect, it is different from the concept or meanings, which are to be the same for all minds.

For example, the concepts of a mammal or a 90-degree triangle are the same for us all. However, intuitive verification of what one has in mind, must be seen by a particular person or invoked by the intelligence of a subject. Thus, what is intuitive is not proven, but simply shown. One cannot prove that a given board is black, but one can show that it is in fact the case. Therefore, we can see that intuition is an instrument allowing us to describe an object which we try to cognise, whereas it is obvious that the description of the object is the stage preceding any further conceptual elaboration in a research work.

Thus, intellection is seeing through one's reason of an ideal object or essence without doing anything more than looking at. Seeing without doing anything else than looking at is common to all intellectual and sensory intuitions. This is a matter of a neutral act where "I, the cogniser" am a passive spectator. Intellectual intuition is an act of comprehending as such, where the subject takes, in a passive way, what the object gives to it, without taking a stand toward it. Thus, intellection is the power of judging of our reason thanks to which we can reach the necessary and self-obvious truths, present, for instance, in mathematic axioms. Cossio exploits here the achievements of ancient philosophers who distinguished two fundamental functions and two levels of our reason. One can mention here the distinction of Plato, namely the intuitive thinking (nous) - at the primary level of our reason, and the discursive thinking (dianoia) - at the secondary level; but also, respectively, the distinction of Aristotle, namely the direct and nondemonstrative knowledge as well as the direct and demonstrative knowledge (Arystoteles 2003; Dębowski 2000, 101 note 102, and 132 note 43).

\subsection{Natural Objects}

Characterising the specifics of natural objects' cognition, Cossio concludes that the method of their examining is the empirical-inductive method (Cossio 1948, 355). Natural sciences demonstrate that.

To induce means to start from facts and get out from them, by abstraction and generalisation, a principle which is conceptual and general. Such approach starts from that what is detailed and leads to that what is general and from what is exact to notions. Such approach is important in its factuality as it is based on a natural experience in compliance with the experience as such. It is something given and created once and for all, as all changes and transformations which we can observe 
in phenomena are the symptoms of such identity, known as a function in a steady, cause-effect correlated constancy. The conclusion is the declaration and not the apodictic truth, as facts are the starting point here. And we already know what characterises factual truths. Basing on this staring point, the empirical-inductive method is a complete instrument of truth. This way the truth about nature is cognised.

Analysing the act of knowledge or gnoseological act, which the empiricalinductive method includes, and from which it gets its meaning, Cossio calls it an act of explaining. To explain something is to break it down into elements for analysis. Its immanent feature is that we refer to something as an effect of something else constituting a cause. In both instances, Pucciarelli says with great concision that "we focus our attention beyond the object as such in the direction of the cause or its components. Therefore, explanation means to refer the fact to something external and to reconstruct it as a synthesis of factors unfamiliar to the fact itself" (Cossio 1938, 320). Moreover, an explanation is a neutral act. The subject cognising does not introduce oneself to the object or does not make any personal stand toward the object. In the course of explaining, the object is cognised through reference to that what is "different" from it. Thus, we move from its intuition to some other kind of intuition and get to know it as a function of the other intuition. To illustrate the process, we may consider the knowledge about what it means to give birth to a child, so different from the point of a mother and a physician assisting her with his conceptual wisdom.

Kant demonstrated that in the natural experiment, we always find two classes of heterogenic elements. On the one hand, we have a conceptual structure which is intelligible in itself, and at the same time rational, provided that the notions are thought about by an intellect. On the other hand, we have an empirical content which our sensory intuition comprehends.

Let us consider any physical law, for example, such which talks about metal expansion when heated. The conceptual structure of our example would consist in the following scheme or form of reasoning: for a given A, B is a real given factor to challenge the law. I have a piece of metal and flame in front of me. Referring to this particular case, I should have therefore said: with a given piece of metal and flame which approaches it, the expansion of the metal is a necessity.

Kant applied a two-fold order of characteristics to label the differences, dividing those applying to structure from those applying to the content of a natural experiment, as it is presented in the table below:

\begin{tabular}{|c|c|c|}
\hline Characteristics No 1 & $\begin{array}{c}\text { Elements of natural } \\
\text { experiment }\end{array}$ & Characteristics No 2 \\
\hline formal & logical structure & necessary \\
\hline material & empirical content & potential \\
\hline
\end{tabular}


According to the first characteristic, the structure is formal and the content is material. The structure of experience consists of its form and nothing more, constituting the "as is" of the experiment. The structure in itself is a matter of a maximum emptiness in its unreality. On the other hand, the content of experience is a part of our knowledge, i.e. "what it is" in the experience. The content in itself is blind as an amorphous mass. Natural experiment which science reveals to us in its authenticity and entirety is a synthesis of both elements as a relationship of form and matter.

According to the second characteristic, logical structure is imperative and universal, as well as constant. However, the content is random and we can consider it as effective, solely if the intuition has communicated its existence to us by means of present action.

Such analysis of experience related to natural science as a physical science, breaking it down into logical structure and empirical content, offers us some distinctive features. First of all, we must conclude that the analysis is comprehensive. There is nothing more in the existing experience than such imperative form and such potential content. However, if we eliminate the logical structure, nothing remains of what the experience offered to us from the start in real unity.

Second of all, the analysis describes intuitive experience, which we know, as it is given to knowledge without making reference to any other explaining notions. In fact, we find in it the formal structure and material content. For Kant, the concept of form is solely for descriptive use, widely proven by modern science. In this Kantian and scientific sense, purely descriptive, the concept of form is widely used as we find it everywhere - in geometric forms of bodies, forms of movement, either slow or fast, etc. As Kant remarks, perception also has to have its forms (in this case, a logical form). Kant's interest was focused on the basics of science. This way, he made a distinction between the forms of knowledge and the forms known by knowledge. The forms of knowledge appear to be the logical forms of experience, in general, always thought about in the same manner and thus such forms are equal for all experiences as their structure a priori. On the other hand, the geometric, kinetic, thermal, and other forms, being integral elements of things, are the forms known in the experience of things as such and similarly to them are the potential content of experience. However, they are not the forms of the same experience taken as an object of reflection. It is not feasible to talk about form, except for logical or conceptual form of experience expressed in knowledge. The distinction between the form of cognition and the form as is known, mean therefore means in the first place the scope and function of logic in the description of a scientific work. The forms of cognition are conceived, the forms known are intuitive. The problem was differently presented in the scholastic philosophy originating from Aristotelian philosophy in which the concepts of matter and form are connected with the 
concepts of potency and act, while the concept of act is connected with the concept of purpose. The form which the things we see have, gives them an inherent purpose provided that this constitutes an achievement of a certain level of being. It is apparent that we discuss here the metaphysical interpretation of what is known in experience and not the positive description, the only starting point for scientific knowledge.

The bottom line is that the two characteristics of experience related to natural science are perfectly overlapping each other: what is formal is necessary and what is material is potential. As the former refers to the conceptual structure, is declared in the truths of reason, namely the truths which exist a priori and are independent from the experience as such. On the other hand, what is material or potential, is expressed in the truths of facts which are a posteriori truths with regard to the experience on which they are based. Thus, the equivalence of the formal, necessary and a priori is systematically applied by Kant in his work Critique of Pure Reason (Kant 1996, 10, 46, 93, 147-149, 162, 228, 265-266). The reasoning of the philosopher concerns the problems arising in the Euclid's mathematics, Newton's physics or rational metaphysics, whereby it is true that the knowledge about nature, as to the form or structure of experience related to natural science, bears these three features.

\subsection{Cultural Objects}

Cultural objects are characterised by the following features: they are real, given in experience, and subject to evaluation.

Cultural objects comprise two elements: a substratum and its meaning. The example given by Cossio to demonstrate their mutual relations is the classic Venus de Milo statue. The substratum of the statue is marble shaped by a sculptor. Therefore, it is a material object, a real one, perceived by us in the sensory intuition. Simultaneously, however, the block of marble as a cultural object has a defined meaning which penetrates the marble and thus, we can say about the sculpture that it is beautiful. The meaning of a cultural object is an "objectifying intention incorporated in the substratum", recognised as "the cognition of what is expressed by the substratum" (Wróblewski 1966a, 7). However, the meaning can exist solely based on a value with which it is united, thus, cultural cognition is the cognition of value. Therefore, "the meaning as an objectifying intention, which is the cognition of what is expressed by the substratum, unites with values and comprises the evaluation of the cognising subject." Thus, we can talk about the meaning " $(. .$.$) as a synonym for a specific positive and negative value, expressed$ by the substratum" (Wróblewski 1966a, 7).

Therefore, in one act of cognition inherent in cultural objects, a twofold intuition occurs. To cognise the substratum, we apply "sensory intuition", while, 
to cognise the meaning, we apply the "emotional intuition of value" (Wróblewski 1966a, 7).

What does it mean that cultural objects have value? Cultural objects are not values as these are not the reality. Value fits into or presents itself as a feature in goods. The Venus de Milo statue is not a beauty as a value. It only bears the value inside, and we say that it is beautiful. Likewise, we do not say that "this is whiteness", but "this is white", as this is the colour of the marble that the statue is made of.

Here we see the difference related to the world of nature which is neutral to value. Beauty which we see in the Venus de Milo statue, being a cultural object, assumes the existence of the meaning which we call beauty. All cultural objects exist as attributing meaning in some aspect. If this is a sculpture, it will be beautiful or ugly, to a greater or lesser extent. If this is a tool, it will be useful or useless. If this is law, it will be just or unjust. Neutrality or indifference against such values is not feasible. Without such axiological meaning, a cultural object does not exist as such, its substratum exists solely as nature. Besides its meaning, the Venus de Milo statue is solely a certain number of pounds of marble which has the same features in a laboratory as any piece of marble.

Cossio believes that meaning exists solely if it emerges in the psychological conscience of a subject. It means that to experience a meaning, it requires the participation of a human - "live phase of meaning" (Cossio 1948, 355). Therefore, the subject cognising cultural objects must be involved in what it cognises, as its experiences are imperative for the meaning to exist (Wróblewski 1966a, 7).

The result of the hitherto considerations is astounding. They have demonstrated that the existence of a cultural object not only requires the existence of a substratum, but also the existence of a live phase of meaning, which is, out of necessity, the psychological and personal existence. The conclusion will be proven when we see that each truth which declares something neutral about an object, may be expressed in an independent judgement, without the necessity to make reference to the object. For example, if I say that the Earth travels around the Sun, such truth, in no way, depends on me and in order to understand it, it does not have to be supplemented with any reference to a person who articulates it. On the other hand, when I say that the Venus de Milo is beautiful or that a fur coat is useful as it protects from cold, the full understanding of such judgements requires making reference to the subject. The Venus de Milo sculpture is beautiful, the fur is useful as it protects from cold, but it is not useful for a stone or a polar bear. Therefore, we see that in the cognition of cultural objects, the subject cognising is not the spectator who only notices a fact, but, in a certain form, presents the fact to revive the meaning as such revival is imperative for their existence. The existence of meaning is characteristic for cultural objects. One may say that this gnoseological act requires personal stand from the subject cognising, as it penetrates the object 
cognised and always sees it from inside - from this or other perspective, from this or that position. A human sees the cultural object and its meaning.

An act of knowledge owing to which a method is created, allowing us to understand cultural objects, is called cognition (Cossio 1948, 350-362). Dilthey believed that we explain nature and understand culture (mental life), (Kuderowicz 1967, 144). We can now say that understanding means seeing a meaning in something - it does not exist without the participation of a human. The subject cognising inserts meaning into reality which it understands. Hence, it looks as understanding is something similar to intellection. It is also seeing by means of intelligence, but this is not the seeing which assumes nothing more than seeing. Such seeing refers to I. Something like this does not occur in intellection, where the seen one is seen as it is, but with a seen quality, as the quality does not create the "being" of the (ideal) object. On the other hand, in the meaning of what is seen, the quality creates the "being" of the (cultural) object.

If we love someone, we love with the quality of such loved one. It is feasible, as being loved creates the object loved. This example is particularly illustrative, as it is undeniable that being loved is a quality which the lover inserts and which creates the object as he loves it as something which is loved. We should say that this is not only loved as he loves it, but at the same time, that he loves it as it is loved. Thereby, the understanding of the phenomenon of love may not be seen solely as a result of associational psychology, as if the loved object was the cause foreign to the feeling of loving which creates such feeling as an effect in the loving one. This way, understanding the phenomenon of love may not be seen solely as a result of associative psychology as if the loved object was the cause foreign to the feeling of loving which makes such feeling as an effect in the loving one. It is clear then that the feeling defines the object and the one being loved acts as the loved one. The same way, when we characterise law as right or wrong, while thinking about actions which it shapes, such characteristic is not the effect of the influence of law on the cognising subject, but is the meaning of conduct assigned by law and as such, the quality of such conduct; what's more, such meaning is attributed by the consciousness of the cognising subject, and exists solely as a consciousness of someone. Here as well, to be right or wrong makes an existence of conduct attributed by law and in it, we evaluate it as right, so the judgement that the subject cognising makes is a part of what he or she sees in the object evaluated. Therefore, it seems that we admire the Venus de Milo not only because it is beautiful, but as the same time because it is a beauty in itself. The same is true for a judicial decision and its fairness, but in case of the first and the second example, we may express ourselves better, separating unity from both dialectic moments. We should say that we approve a judicial decision as it is fair; understanding that it is fair in itself and we judge it correspondingly. We achieve it owing to the act of knowledge called understanding which is an act similar to ontological nature of cultural objects. Thus, "to judge" means "to know". 
This gnoseological act of understanding somewhat resembles explaining. In fact, understating refers something to another thing which is not the same as the thing. We have already seen that a cultural object requires the existence of a substratum in which its meaning is shown and the existence of the reality of the meaning. It is not essential whether a substratum may be a fragment of a physical world as it is exhibited in objects (canvas and colours of a painting, sound vibrations in music or poetry, etc.), or that a substratum may be sole acts of human behaviour as it is exhibited in egological objects. Therefore, in the gnoseological act of understanding, we relate one of the events to the other one. We can either raise from the materiality of the substratum to its meaning, as this is the case of objects already created, or go from the meaning to the substratum, as this is the case in the process of creating, called inspiration.

Whereas, the act of explaining progresses without reversing in the same direction, indicated on exit (e.g., from cause to effect), the act of understanding, on the contrary, returns, after the first reference, to its staring point where it, again, returns to the previous reference and so, gradually, in an endless circular motion which follows from the substratum to its meaning and vice-versa. Knowledge attained through understanding is being created and completed with an exit at a certain point which selects an explanation in a way that what it summarises in a synthesis, is always a known object and something which is not. On the other hand, knowledge through understanding which is created and completed also by exit from this circular motion at a certain moment, is done without coming outside. In case of knowledge attained through explanation, when one reverses toward a direction selected by a cognising mind, the knowledge does not grow as what has been already explained, remains entirely known. On the other hand, we are to learn that each time one goes back to the previous stage, one extends knowledge through understanding.

According to Cossio, a method relevant to cognise cultural objects is the empirical-dialectic method (Cossio 1948, 350-362), which is a reference to a construction of the hermeneutic circle of Martin Heidegger. It is about the fact that cognition through understanding moves in a "circular motion" between a substratum and a meaning, as we cognise the substratum through meaning, and meaning through substratum. Thus, we dialectically reach the final cognition which is "a simple, but open entirety". One cannot distinguish here individual stages. As we deal here with a continuous stream of cognition which finally leads us to consistency between the substratum and its sense (Wróblewski 1966a, 8).

In general, dialectic is a synthesis made by a spirit through own spontaneous activity of a thesis and an alternative thesis (antithesis), in the function jointly summing up the implication of a hidden meaning. Thus, we have access to cultural objects. Their understanding circles around from the substratum to the meaning and vice-versa, making one to become a thesis and the other one, an alternative 
thesis. Such understanding is not feasible through induction, as nothing is generalised in their knowledge. To base on induction, a human who has always seen ugly sculptures would conclude that the Venus de Milo statue is also ugly. Such cognition is also not feasible through deduction, as we lack an intellectual proof for it, which would have to serve as a starting point for deductive reasoning. Unless, we would agree, after Plato, that knowledge originates from a metaphysical reminiscence of what the soul had seen prior to our birth. Cultural objects are cognised in dialectic form which transits from materiality of a substratum to the reality of its spiritual meaning and vice versa.

If we observe mathematical knowledge and the process of its attainment, we can notice that it is attained as a "simple and closed entirety", without going through various stages or individual parts. Whoever knows the principles of adding and must add a value, starts an operation and continues it without transitions and breaks till the end. Then, he or she may find whatever he or she was looking for. Such knowledge does not grow bigger, if someone proves it through repeating the operation. It is as full and comprehensive for a mathematical specialist, as for a young student.

While observing nature related knowledge and the process of its cognition, we note that it is attained as a "complex, but open entirety", going through separate stages or various parts, e.g. when one attempts to determine the forces which caused a movement. The determination of each factor entering as a cause or a component of an effect is accomplished by a separate step which reveals nothing in relation to them and which may be continued separately. As soon as one gets a result, namely just after the cause of movement is established, one may still continue establishing the causes. Such knowledge increases toward the direction of an open horizon.

On the other hand, if we observe the knowledge about culture and the process of its cognition, we note that it is obtained as a "simple, but open entirety" without going through separate stages or parts, but with continuous and fluent increment in knowledge. We have already seen the simplicity of a cultural object, as the substratum and its meaning are not two alien and external things, but two components which, after mixing, form a unity. Despite this fact, each time such cultural knowledge transits from substratum to its meaning in its circular movement, and further from the last one to the previous one, etc., the cultural knowledge increases and cognises the object better and better. Let us think about a player who keeps improving his sports skills; this is not just the automatism of muscles or the improvement of the organic substratum, but also greater understanding of the essence of the sport. Let us think about music which we understand better the more we listen to it. Let us think about nuances which we find in philosophical works each time when we read them again. Such nuances reveal along with further reading. In all this, we see how the knowledge gets deeper and becomes confirmed by understanding 
each time when it returns according to the specifics of the hermeneutic circle movement. This is the case of a judge who intends to declare the decision made. The judge considers a given case in all its complexity and further its legal relevance which will be reflected in the decision. Further, the judge goes back to the case to see whether it truly suits its meaning. In turn, the judge goes back to formulating the decision, possibly emphasising a given circumstance which went unnoticed upon the first investigation of the case. Again, the judge goes back to the case and its circumstances, possibly, underlying what an article of the code states or maybe solely with a greater sophistication of the legal meaning of the case. And thus, the judge continues the circular movement which goes from one activity to another, while the judge's knowledge grows in strength and clarity. This is knowledge through understanding. When the judge is finally convinced, he or she makes the decision which is a result of such understanding of the case as should be, and at the same time presents the decision in a conceptual form.

The question is whether one can talk about any objectivity of such cognition, in the light of such perspective on the gnoseological act of cultural objects cognition, which, after all, is of evaluative nature. This is not only about objectivity consisting in the existence of material substratum and the existence of sense in experiences which are objective as possible in experience ("plausible objects of experience" as Cossio formulates referring to Husserl).

The issue concerning the objectivity of evaluating as emotional recognition of valuable objects is more complex, which, by definition, all cultural objects are. Here, Cossio gets the answer confirming the objectivity by reference to Husserl's understanding of objectivity as intersubjectivity. Therefore, the objectivity of individual evaluation may be determined by comparing it with social evaluation, which is the source of objectivity. The products being compared are two concepts of sense, being at the same time its emotional experience - the concept is to serve here as a part of the experience. Eventually, the objectivity of evaluation will be to determine the relevance between the substratum and the socially determined sense. Understanding, which we utilise in law, is the "conceptual-emotional" understanding - which is described by the phenomenology of legal cognition beside such as "unconstrained emotional understanding" (present in arts) or "intimately emotional understanding" (present in morality) (Wróblewski 1966a, 9).

In the conclusion of the above considerations, it should be stated that for egology it is appropriate to refer to the concept of cultural object being the effect of human activity. From the perspective which is of our interest, the cultural object is a certain unit of sense, a certain type of meaning which we give to substrata. It is claimed here that the relationship between the meaning of cultural objects and reality is of no causative nature. The conclusion from such reasoning is the epistemological thesis boiling down to the claim that interpretation is the manner of cognition of cultural reality. 
Below, I present the schematic classification of objects and gnoseological methods attributed to them as well as the acts of knowledge specific for the cognition of such objects.

\begin{tabular}{|c|c|c|}
\hline Types of objects & Gnoseological methods & $\begin{array}{c}\text { An act of knowledge utilised } \\
\text { by a relevant method }\end{array}$ \\
\hline ideal & rational-deductive method & $\begin{array}{c}\text { intellectual intuition } \\
\text { (intellection) }\end{array}$ \\
\hline natural & empirical-inductive method & explanation \\
\hline cultural & empirical-dialectic method & understanding \\
\hline
\end{tabular}

This is how the major cognitive issues are, related to the regions of ideal, natural and, particularly, cultural objects. In relation to the concepts of regional ontologies which has been only outlined by Husserl in his "Ideas I", Cossio developed it considerably and created the original phenomenology of cultural cognition.

\section{LAW AS A CULTURAL OBJECT}

The Philosophy of law by Cossio stands in a radical opposition toward the traditional legal thinking. As it assumes that the legal dogma is a science about reality and the knowledge of experience. However, egology is all about human or cultural experience, and not about nature-related experience. And this is what differentiates it from the legal (dogmatic) rationalism, as well as from legal empiricism, predominating law.

The representatives of rationalism believe that objects which a lawyer cognises, are the regulations and standards and that the positive law does not present them and they cannot be achieved through senses. According to this, the legal dogma is a knowledge about ideal objects as the rules are cognised by a thought as objects in mathematics, for they are neither seen nor touched.

On the contrary, the representatives of empiricism object to such idealism in law, accept the realism of regulations and standards, claiming that the legal knowledge is based on what legal experience reveals. However, it does not acknowledge any other contact with experience as through sensory intuition only, which enables us to cognise nature so the legal knowledge acquires knowledge through reference to other real events. For example in the instances when law is interpreted through reference to possibly exact intent of persons who passed it, taking into consideration the relationship between the fact and law (Cossio 1948, 345-348).

In contrary to legal rationalism, egology anticipates that the objects which should be known to the lawyer are not the rules, but human behaviour at which 
we look from a certain perspective. In the same way as stars are the objects of astronomy and not the Kepler's and Newton's laws, as they are concepts solely, on which we base our knowledge of stars, thus in dogma, the objects of the lawyer's knowledge are not the rules, but human behaviour in its intersubjective impact. The rules are just the concepts with the help of which we think about such behaviour. As such, the concepts are the ideal objects of logical type as all other concepts. Therefore, considering rules as such is a concern of formal legal logic and Hans Kelsen's research - known as a pure theory of law - comprise its outlines and fundamentals. But dogma, as far as it is the knowledge of reality, includes something more than legal logic, which comes directly from human experience, like natural experiment brings to physics something which does not originate from the sole logical structure of knowledge about nature. It can be illustrated by the following example: with the same logical structure and not compromising the formal rights of thoughts (which ipso facto would invalidate knowledge), we may imagine that if the distance between two objects " $\mathrm{A}$ " and " $\mathrm{B}$ " is reduced, this is because "A" moved closer to "B" or because "B" moved closer to "A". The two possibilities of moving closer seem to be equal in logical rights of thoughts. And if this is the fact that "A" moved closer to "B", and not the other way around, there is something more in the knowledge which is added by intuition to the logical structure as a cause which supports experience.

In contrast to legal empiricism, egology assumes that human behaviour is the subject of experience which is entirely different from the experience of natural objects as they constitute an imperative experience managed by the similarity of causes and effects, while human behaviour constitutes the subject of experiencing freedom which imperative feature is to create, each and every time, something unique. This is the reason why we cannot think about behaviour as of a being, for human behaviour, as the experience of freedom, is a constant opportunity. In legal terms, it thus exists solely as something which should be (Cossio 1948, 348).

Thus, Cossio claims that only through the philosophy of law, presenting human behaviour as it should be, we may have dogma which, only then, would be a science dealing with legal reality. Therefore, egology adopts the normative logic of pure theory of law which has shown that legal rules are only concepts with the use of which we think about behaviour. If, however, legal dogma is to be the science dealing with reality, it must also study the special intuition of law which is the intuition of freedom possessed by everyone based on human experience. Thus, only when we take into consideration this axiological intuition, as well as logical and legal structure, which, according to Cossio, the normative logic of pure theory of law is, we can get a bigger picture of a legal phenomenon.

As we can see, Cossio believes that the relevant object of law is human behaviour while legal standards are solely concepts by means of which we can qualify such behaviour as forbidden, permitted or legally neutral. Thus, egology 
recognises law, inter alia, as a fact. Therefore, the fundamental aim of egology becomes the aim to examine behaving as the relevant object of law.

I will now proceed to trace the role of cultural cognition phenomenology in terms of the concept of law and legal cognition. Egological philosophy of law derives from the phenomenological description of a given essence of law, directly. The reason for this is that the phenomenological method boils down to the examination of the essence of objects. The starting point here is a special cognition of the essence in the act of intuition of essence, namely the intellectual intuition. Eidoi are the subjects of the intuition, while egology describes cultural objects building on the concept of regional ontologies.

Cossio divides cultural objects into two major groups. The division is held at the ontic level and its criteria is the type of substrata making up cultural objects. If a product of human behaviour is the substratum, then, according to the Heidegger's terminology adopted by Cossio, we will deal with the objects of the world; on the other hand, if the human behaviour itself is the substratum of a cultural object, then we will deal with egological objects (Wróblewski 1966a, 9). The first type of the cultural objects constitutes the "world" of human existence, in other words, they are the objectified life of a human. The second type of objects is the human behaviour, the behaviour of ego; Cossio defines it also as a living human life (Cossio 1948, 368).

Cossio emphasises that cognitive intuition related to each and every cultural object is of dual nature. On the one hand, at the ontic level, we deal with the intuition of a substratum, which is the sensory intuition; on the other hand, at the ontological level, we deal with the intuition of sense, which is the emotional intuition. Although, the critical factor on which the existence of a cultural object depends, is the experience of its meaning, however such object is "physically located" where the substratum already exists, so - in the instance of egological objects - in the individual (ego) (Wróblewski 1966a, 9). The last remark explains why the discussed theory is called "egological" by its creator.

Egological objects (cultural) are of a unique status of being, entirely different from any other objects. Egological objects are neither natural objects, nor metaphysical ones, and moreover they differ from ideal objects. Adolf Reinach presented a similar view (Bekrycht 2009, 74).

Law is an egological object, as Cossio concludes, based on the intuition connected with ontic existence of law, that law belongs to culture and is intuitively recognised as a behaviour. However, such behaviour must be considered according to the Heidegger's thesis that the characteristic feature of human presence is co-existence in the world. It concerns the behaving considered in relation to any other behaving of various people who may disturb such given behaving (Wróblewski 1966a, 10). Such statement leads us to the determination of law at the ontic level as "a behaviour of a human considered from a certain perspective - in its intersubjective interaction" (Cossio 1948, 348). Therefore, it seems that 
to determine what in fact law is, we do not need any legal standard. "As for egology, the subject of legal knowledge is human behaviour considered in its intersubjective interference, while standards constitute solely imputable concepts to which the behaviour refers (...)" (Cossio 1948, 369).

In turn, from the ontological perspective, law constitutes values which are inherent in behaviour. The relationship between values and behaviour is very close as "from ontological perspective, behaving without value may not exist" (Wróblewski 1966a, 10). From ontic perspective, behaving presents as an existential duty, while from ontological perspective, as axiological duty.

The philosophy of value originating from phenomenology, does not attribute any real being to values. However, it does not believe that, at the same time, values lack any being, so we would be forced to boil them down to the acts of evaluation (to judgement). Axiological phenomenology argues that values are something in between of what is real and the act of evaluation. They are not real, some of them only call for realisation, like justice, for example. However, values are not solely subjective in this perspective. They are given as objects which attract us or repel. Therefore, phenomenologists say that values are objective (Tischner 1982, 271). Applying the terminology of Cossio, one may say that values do not float above the surface of life as timeless creations, but remain full of temporary freedom in the existential future, which exhibits them, depending on the radical structure of its own presence as a metaphysical presence (Cossio 1964, 564-565).

The relationship between behaving and values results from the fact that behaviour is a way of human existence, thus occurs in the existential time which varies from the natural time. Egology derived the concept of time from Husserl's philosophy (Husserl 1989, 32-108), while the concept of existential time - from Heidegger. According to it, the core of all metaphysics shall be the metaphysics of time, as human is a being deeply penetrated by time. There are specific relationships between past, presence, and future in the existential time.

Heidegger claims that the circular nature of thoughts is not its lack - on the contrary, owing to this a thought reveals reality. The hermeneutic circle is a dialectic unity of going back and ahead; accordingly, the basis of the future is what has already been and the past depends on projecting. Thus, interpretation is of timely nature. What is subject to interpretation, always belongs to the past and the present interpretation gives it a new meaning, influencing at the same time its future understanding. Each interpretation links the past with the future and is, at the same time, the product of its time. The described time-related relationships enable us to go from being to duty, which is related to the assumption that values are connected with the future considered from ontological perspective.

It is impossible not to notice that the above presented assumption made by Cossio in terms of ontological possibility of going from being to duty is 
characteristic for the advocates of the concept of natural law. Therefore, it could appear that egology investigates law from ontological perspective.

For egology, assuming that law is each and every common behaving consisting in subjective interference, the legal value is each dual value. Thus, Cossio created a "pure axiology of law", setting out from Heidegger's claim that human life is coexistence. The scope of the mentioned dual values determines the "legal axiological tangle" including three pairs of legal values:

- order and security, characterised in the context of "human coexistence as a situation";

- power and peace, characterised in the context of "coexistence in relation to persons"; and

- cooperation and solidarity, characterised in the context of "coexistence depending on society".

Justice wins a special position amongst legal values. Pure axiology of law analysed the social character of justice as an overriding legal value. Its specific character is that it harmonises the remaining legal values. Justice is described by Cossio in the context of "coexistence depending on sufficient rationale". Besides, justice is the value which the law serves, realising the existential freedom of a human (Cossio 1964, 563).

Thus, egology finally reaches the determination of law as behaving in intersubjective interference at ontic level which is a value on the ontological plane.

\section{CONCLUSION}

To conclude the above considerations, I will try to situate egology in the disputes regarding what in fact law is or what is it that we call law. The reference plane here will be the dispute between the advocates of the concept of the natural law and the legal positivism.

At first, it could seem that Cossio in his views is closer to the advocates of the theory of the natural law. The evidence for that could be the fact of originating the essence of law from ontological perspective. This applies to treating law as a cultural object. The second aspect which could suggest affiliation of Cossio beliefs with the advocates of the natural law is assuming the possibility of transition from being to legal duty, connected with the M. Heidegger concept of existential time.

In my opinion the conviction that egology belongs to the theories related to the group of natural law is not correct. It results from a false, common-sense interpretation of Cossio's theory. Because egology does not fall within the frames of dispute concerning the essence of law. We must remember about the fact that Cossio uses the phenomenological method, while phenomenologists use the term "ontology" in the meaning of a phenomenon. Thus, in the case of egological 
theory, we may not use the term ontology in the meaning of metaphysics, in the arche meaning, i.e. the explanation of the beginning and the search of what is the principle of all things and their aim. Using the methodology developed by Husserl, Cossio seeks the concept of law as a semantic category. He poses neither ontological nor metaphysical questions concerning law; he does not ask what in fact law is or what it is that we call law (Stróżewski 2006, 94). Cossio studies the content of the concept of law, he does not attempt to reveal the designate of the concept of law owing to which the said concept gets on its meaning (Stróżewski 2006, 59). Thus, the philosophy of law by Cossio is of semantic nature.

Adolf Reinach presented similar stance as to the way of understanding its own philosophy of law. He, similar to Cossio, studied law with the application of phenomenological methodology. His dissertations on the foundations of civil law were frequently interpreted as an attempt of going back to the old concept of natural law, which Reinach himself strongly opposed (Spiegelberg 1960, 202).

In the conclusion of the article, it should be also stated that the distinctive feature of the egological theory is the belief that the philosophy of law may not be developed the same way as natural sciences. Adopting such stance in the dispute between the naturalistic and antinaturalistic approach, Cossio touches presently significant issue of both the philosophy of law and the philosophy in general. Essentially, the point is whether they may reach the reliable and objective knowledge which may be obtained through the application of natural science principles or whether one should adopt the hermeneutic attitude. Such attitude enables posing questions about the sense of human life, about the foundations of knowledge studied on the basis of the attitude comprehending the reality of the senses created by human (Zirk-Sadowski 1982, 7). The choice made has weighty implications relating to the manner of philosophical practice, in particular, methodological and axiological implications, hence, also philosophical and legal ones.

\section{BIBLIOGRAPHY}

Arystoteles. 2003. Dzieła wszystkie. Vol. I. Warszawa: Wydawnictwo Naukowe PWN.

Bekrycht, Tomasz. 2009. Aprioryczność prawa, Ontologia prawa w fenomenologii Adolfa Reinacha. Warszawa: Wolters Kluwer Polska.

Cossio, Carlos. 1948. "Phenomenology of the decision". In Latin-American Legal Philosophy. 343400. Edited by Luis Recasens. Cambridge, MA: Harvard University Press.

Cossio, Carlos. 1964. La Teoria Egologica del Derecho y el Concepto Juridico de Libertad. Buenos Aires: Abeledo-Perrot.

Cossio, Carlos. Eugenio Pucciarelli. 1938. "La comprehension en Dilthey". Humanides 26: 320.

Dębowski, Józef. 2000. Bezpośredniość poznania. Lublin: Wydawnictwo Uniwersytetu Marii Curie-Skłodowskiej.

Dilthey, Wilhelm. 1958. Gesammelte Schriften. Vol. V. Stuttgart: Teubner. 
Husserl, Edmund. 1989. Wyktady z fenomenologii wewnętrznej świadomości czasu. Warszawa: PWN.

Ingarden, Roman. 1963. Z badań nad filozofia współczesna. Warszawa: PWN.

Kant, Immanuel. 1996. Critique of Pure Reason. Vol. I. Indianapolis: Hackett.

Kuderowicz, Zbigniew. 1967. Dilthey. Warszawa: Wiedza Powszechna.

Martel, Karol. 1967. U podstaw fenomenologii Husserla, Warszawa: Książka i Wiedza.

Spiegelberg, Herbert. 1960. The Phenomenological Movement. Vol. I. Dordrecht-Hague: Springer.

Stróżewski, Władysław. 2006, Ontologia. Kraków: Znak.

Tischner, Józef. 1982. Myślenie wedlug wartości. Kraków: Znak.

Wróblewski, Jerzy. 1957. "Fenomenologiczna filozofia prawa w Ameryce Łacińskiej”. Państwo i Prawo 6: 1185-1197.

Wróblewski, Jerzy. 1966a. "Filozoficzne założenia podstawowych pojęć egologii."Zeszyty Naukowe Uniwersytetu Łódzkiego. Seria I 44: 3-31.

Wróblewski, Jerzy. 1966b. "Postawa filozoficzna i afilozoficzna we współczesnej teorii prawa". Studia Prawnicze 13: 60-89.

Wróblewski, Jerzy. 1969. "Prawo i płaszczyzny jego badania". Państwo i Prawo 6: 996-1006.

Zirk-Sadowski, Marek. 1977. "Prawo a kultura". Zeszyty Naukowe Uniwersytetu Łódzkiego 19: $29-42$.

Zirk-Sadowski, Marek. 1982. "Hermeneutyka a problemy filozofii prawa". Studia PrawnoEkonomiczne 28: 7-25. 